\title{
Performance of the STOP-Bang in the Detection of OSA, a Brazilian study
}

\author{
(iD) úlio Cezar Rodrigues Filho ${ }^{1}$ \\ (iD) Denise Duprat Neves ${ }^{2,3}$ \\ D Maria Helena de Araujo-Melo ${ }^{3,4}$
}

\begin{abstract}
1. Doutorando em Neurociências pelo PPGNEURO/UNIRIO, Rio de Janeiro, RJ, Brasil 2. Departamento de Medicina Especializada - Disciplina de Pneumologia da Escola de Medicina e Cirurgia, da Universidade Federal do Estado do Rio de Janeiro, Rio de Janeiro, RJ, Brasil

3. Pesquisadora do Laboratório do Sono do Hospital Universitário Graffrée e Guinle/UNIRIO, Rio de Janeiro, RJ, Brasil 4. Departamento de Medicina Especializada - Disciplina de Otorrinolaringologia da Escola de Medicina e Cirurgia, da Universidade Federal do Estado do Rio de Janeiro, Rio de Janeiro, RJ, Brasil
\end{abstract}

http://dx.doi.org/10.1590/1806-9282.65.7.995

\section{SUMMARY}

OBJECTIVES: Assess the performance of the Stop-Bang questionnaire in Brazilian patients for the screening of OSA.

METHODS: A cross-sectional study with historical and consecutive analysis of all patients who underwent polysomnography tests in the Sleeping Sector of the Ear, Nose, and Throat, and Cardiopulmonary (LabSono) Departments of the Gaffrée and Guinle University Hospital (HUGG), from 10/17/2011 to 04/16/2015. The variables relating to the SB questionnaire were collected by direct research from the medical records of patients.

RESULTS: In a series of 83 patients, we found that our sample were similar to other studies conducted in specialized centers of Sleep Medicine, and the population presented characteristics similar to those found by studies in Latin America. Men and women only behaved similarly in relation to the presence of Observed Apnea and body mass index, with a predominance of women who had systemic hypertension over men. In our study, the discriminatory value of 4 or more positive answers to the questionnaire had the best performance in identifying patients with an hourly Apnea-Hypopnea Index greater than 15/h, with a sensitivity of 72.97\% (55.9\% - 86.2\%) and specificity of $67.39 \%(52.0 \%-80.5 \%)$.

CONCLUSIONS: The Stop-Bang questionnaire proved to be, in our sample, a good screening instrument for diagnosing OSA Syndrome. KEYWORDS: Sleep Apnea, OSA Syndromes. Surveys and Questionnaires. Polysomnography. Diagnosis.

\section{INTRODUCTION}

The prevalence of Obstructive Sleep Apnea (OSA) is still controversial. It is estimated at an average of $22 \%$ among men and $17 \%$ among women'. Many cases still remain with no definite diagnosis ${ }^{2}$. Full-night polysomnography (PSG), at specialized sleep laboratory and in the presence of a qualified technician, is the chosen method (gold standard) for diagnosing respiratory sleep disorders ${ }^{3}$. However, it is expensive, time-consuming, and uncomfortable, in addition to not being affordable for the majority of the population ${ }^{4,5}$. That is why several alternative methods for screening and diagnosis are being researched, from simple questionnaires to smaller and portable devices.

In 2008, Dr. Frances Chung's group, from the Department of Anesthesia of the Toronto Western Hospital, Canada, published an article presenting a questionnaire approach to the screening, the Stop questionnaire. It is a quick and simple questionnaire 
with straightforward yes/no questions that has been used in different scenarios. This tool has changed and condensed the Berlin Questionnaire (BQ) in four items, with special care to have a questionnaire that is concise and easy to use ${ }^{6}$. More than two positive answers in the Stop questionnaire mean a significant risk for OSA. Subsequently, the inclusion of four objective measures was analyzed, resulting finally in a method that is easy to use, with high sensitivity and negative predictive value, especially for cases of moderate and severe $\mathrm{OSA}^{7,8}$, which are desirable characteristics in screening tests. This questionnaire has already been validated for Brasil ${ }^{9}$.

The current study aims to evaluate the behavior of the variables present in the Stop-Bang (SB) Questionnaire in Brazilian patients who underwent PSG in a university hospital in Rio de Janeiro and check its performance for OSA screening in the sample studied.

\section{METHODS}

A cross-sectional study, with historical and consecutive analysis of all 110 patients who underwent polysomnography exams at the Sleep Department (LabSono) of the University Hospital Gaffrée e Guinle (HUGG), from 17/10/2011 to 16/04/2015. All patients who underwent the PSG were informed about the possibility of their data being used in scientific studies, respecting their privacy, and signed the informed consent form (CNS Resolution no. 196/1996). This study is part of a larger project (Study of predisposing conditions and comorbidities associated with sleep disorders) that was submitted to and approved by the Research Ethics Committee of the HUGG under No 37/2011.

We included all patients 20 years old or older with complaints related to OSA and who, therefore, were forwarded to the PSG. We exclude those who did not sign the informed consent form and patients with morbid obesity (BMI $\left.>40 \mathrm{~kg} / \mathrm{m}^{2}\right)$. All the examination reports were done manually, according to criteria previously described by the American Academy of Sleep ${ }^{10}$.

The variables related to the SB were collected by direct research in the patient's medical records and defined as follows:

Original Stop-Bang questionnaire ${ }^{11}$ :

1. Snoring: Do you snore loudly (loud enough to be heard outside your bedroom with the door closed?

2. Tired: Do you feel tired frequently, sleepy during the day?
3. Observed: Has anyone ever noticed your breathing stopping while you sleep?

4. Blood Pressure: Do you have or are on treatment for high blood pressure?

5 . BMI: Is your BMI greater than $35 \mathrm{~kg} / \mathrm{m}^{2}$ ?

6. Age: Are you older than 50 years? Yes or No

7. Neck circumference: Is your neck circumference greater than $40 \mathrm{~cm}$ ?

8. Gender: Are you a male?

Since the data collection was retrospective in medical records, some changes were necessary, as listed below:

Presence of snoring. In this study, we considered the answer to be positive in the presence of any report of snoring.

The PSG was performed using the BrainNet BNT 36 device, with 32 channels, on adequate beds, in a location with appropriate levels of noise, light, and temperature. The results of this test, especially the hourly Apnea-Hypopnea Index (AHI), remained unknown to the researcher until the moment of analysis.

The severity of the Obstructive Sleep Apnea was graded into three cutoff points $5 / \mathrm{h}, 15 / \mathrm{h}$, and 30/h.

The data from the SB questionnaires and the PSG were transcribed into an electronic spreadsheet (Microsoft Excel ${ }^{\circledR}$ ) and subsequently analyzed using the MedCalc $^{\circledR}$ software $^{12}$.

We calculated the absolute and relative frequencies of nominal variables and central and dispersion measures, and the amplitude of the continuous variables to present the sample and variables characteristics per selected groups.

The sensitivity (S), specificity (E) and the likelihood ratios (LR+ and LR-) for the diagnosis of OSA, defined by an AHI $>15 / \mathrm{h}$ were calculated based on $2 \mathrm{X} 2$ contingency tables. The cut off value (DV) of the SB was analyzed by ROC Curve (receiver operating characteristic plots $)^{13-15}$. The significance level was set at less than or equal to $5 \%(a \leq 0.05)$ to reject the null hypothesis in a two-tailed test. The values are presented with the respective confidence interval at 95\% (95\% CI), which expresses with $95 \%$ certainty the range of values within which the true value lies in the population.

\section{RESULTS}

LabSono/Unirio performed 110 examinations by the end of the current study. A total of 27 patients were excluded, 16 due to low technical quality, four 
TABLE 1. CENTRAL VALUES AND DISPERSION OF THE VARIABLES THAT CHARACTERIZE THE SAMPLE.

\begin{tabular}{l|l|l|l|l|l|l|l} 
& Average & SD & Median & Minimum & Maximum & 25-75P & Normal Dist. \\
\hline Age & 48.2 & 11.3 & 50.0 & 22.0 & 69.0 & 40.2 a 56.0 & $<0.0001$ \\
\hline BMI & 30.0 & 5.7 & 29.0 & 17.7 & 47.9 & 26.1 a 33.3 & $<0.0001$ \\
\hline Neck circumference & 39.7 & 4.3 & 39.0 & 30.0 & 49.0 & 37.2 a 42.0 & $<0.0001$ \\
\hline AHI & $23.2 / \mathrm{h}$ & $25.0 / \mathrm{h}$ & $11.4 / \mathrm{h}$ & $0.0 / \mathrm{h}$ & $113.5 / \mathrm{h}$ & $5.2 / \mathrm{h}$ to $33.7 / \mathrm{h}$ & $<0.0001$ \\
\hline
\end{tabular}

Legend: SD - standard deviation, AHI - hourly Apnea-Hypopnea Index, BMI - Body Mass Index ( $\left.\mathrm{kg} / \mathrm{m}^{2}\right)$, 25-75P - percentile between 25\% and 75\% of the sample, Normal Dist. - normal distribution.

TABLE 2. ABSOLUTE AND RELATIVE FREQUENCY DISTRIBUTION OF THE STOP-BANG VARIABLES ACCORDING TO GENDER.

\begin{tabular}{l|l|l|l|l|l|l|l|l} 
Translation & Total & $\%$ & $95 \% \mathrm{Cl}$ & $\mathbf{0}$ & $\%$ & + & $\%$ & $\mathrm{p}$-value \\
\hline Snoring & 79 & 95.2 & $75.3-100$ & 47 & 100 & 32 & 88.8 & 0.0199 \\
\hline Tiredness & 58 & 69.9 & $53.0-90.3$ & 28 & 59.5 & 30 & 83.3 & 0.0201 \\
\hline Apn. Witn. & 53 & 63.9 & $47.8-83.5$ & 32 & 68.1 & 21 & 58.3 & 0.3623 \\
\hline Hypertension & 33 & 39.8 & $27.3-55.8$ & 11 & 23.4 & 22 & 61.1 & 0.0005 \\
\hline BMl>35 & 17 & 20.5 & $11.9-32.7$ & 9 & 19.1 & 8 & 22.2 & 0.7325 \\
\hline Age>50 & 45 & 54.2 & $39.5-72.5$ & 21 & 44.6 & 24 & 66.6 & 0.0477 \\
\hline NC>40 & 38 & 45.8 & $32.4-62.8$ & 27 & 57.4 & 11 & 30.5 & 0.0154 \\
\hline Gender 万人 & 47 & 56.6 & $41.6-75.3$ & & & & &
\end{tabular}

Legend: Apn. Witn. - Observed Apnea, NC- neck circumference (cm), Hypertension, IC95\% confidence interval, BMI - Body Mass Index (kg/m²).

TABLE 3. CHARACTERISTICS OF EACH RANGE OF POSITIVE ANSWERS TO THE STOP-BANG QUESTIONNAIRE AND THE AVERAGE OF THE AHI.

\begin{tabular}{l|l|l|l|l|l|l} 
Stop-Bang & $2+$ & $3+$ & $4+$ & $5+$ & $6+$ & $7+$ \\
\hline Snoring & $66.6 \%$ & $100 \%$ & $100 \%$ & $100 \%$ & $93.3 \%$ & $100 \%$ \\
\hline Tiredness & $55.5 \%$ & $50.0 \%$ & $68.1 \%$ & $69.5 \%$ & $86.6 \%$ & $100 \%$ \\
\hline Apnea & $0.0 \%$ & $50.0 \%$ & $63.6 \%$ & $82.6 \%$ & $73.3 \%$ & $100 \%$ \\
\hline Hypertension & $77.7 \%$ & $10.0 \%$ & $27.2 \%$ & $47.8 \%$ & $66.6 \%$ & $75.0 \%$ \\
\hline BMI>35 & $0.0 \%$ & $0.0 \%$ & $0.0 \%$ & $13.0 \%$ & $66.6 \%$ & $100 \%$ \\
\hline Age>50 & $44.4 \%$ & $20.0 \%$ & $63.6 \%$ & $52.1 \%$ & $66.6 \%$ & $75.0 \%$ \\
\hline NC>40 & $0.0 \%$ & $20.0 \%$ & $22.7 \%$ & $60.8 \%$ & $86.6 \%$ & $100 \%$ \\
\hline Men & $11.1 \%$ & $50.0 \%$ & $59.0 \%$ & $73.9 \%$ & $60.0 \%$ & $50.0 \%$ \\
\hline Average AHI & $6.8 / \mathrm{h}$ & $17.2 / \mathrm{h}$ & $10.2 / \mathrm{h}$ & $27.1 / \mathrm{h}$ & $42.3 / \mathrm{h}$ & $52.7 / \mathrm{h}$ \\
\hline
\end{tabular}

Legend: CC - Cervical Circumference, Hypertension, AHI - hourly Apnea-Hypopnea Index, BMI - Body Mass Index.

TABLE 4. SENSITIVITY AND SPECIFICITY OF THE STOP-BANG VALUES, CONSIDERING AHI>15 INDICATIVE OF OSA PRESENCE.

\begin{tabular}{|c|c|c|c|c|c|c|c|c|}
\hline$S-B$ & $S$ & $95 \% \mathrm{Cl}$ & E & $95 \% \mathrm{Cl}$ & LR+ & $95 \% \mathrm{Cl}$ & LR- & $95 \% \mathrm{Cl}$ \\
\hline 2 & 97.3 & 85.8- 99.9 & 17.3 & $7.8-31.4$ & 1.1 & $1.0-1.4$ & 0.1 & $0.0-1.2$ \\
\hline 3 & 86.4 & $71.2-95.5$ & 30.4 & $17.7-45.8$ & 1.2 & $1.0-1.6$ & 0.4 & $0.2-1.1$ \\
\hline 4 & 72.9 & $55.9-86.2$ & 67.3 & $52.0-80.5$ & 2.2 & $1.4-3.5$ & 0.4 & $0.2-0.7$ \\
\hline 5 & 37.8 & $22.5-55.2$ & 89.1 & $76.4-96.4$ & 3.4 & $1.4-8.8$ & 0.7 & $0.5-0.9$ \\
\hline 6 & 8.1 & $1.7-21.9$ & 97.8 & $88.5-99.9$ & 3.7 & $0.4-34.4$ & 0.9 & $0.8-1.0$ \\
\hline$\geq 7$ & 0.0 & $0.0-9.5$ & 100 & $92.3-100$ & & & 1 & $1.0-1.0$ \\
\hline
\end{tabular}

Legend: E - specificity, 95\% Cl - confidence interval, S - sensitivity, LR - likelihood ratio (positive and negative), S-B - Stop-Bang. 
TABLE 5. PERFORMANCE OF DISCRIMINATORY VALUES OF THE STOP-BANG.

\begin{tabular}{l|l|l|l|l|l|l|l|l} 
Variable & DV & Clas. OSA & S & $95 \% \mathrm{Cl}$ & E & $95 \% \mathrm{Cl}$ & LR+ & LR- \\
\hline & & AHI> 5/h & 60.8 & $48.4-72.4$ & 100 & $76.8-100$ & 0.3 \\
\hline Stop-Bang & $\geq 4$ & AHI> 15/h & 72.9 & $55.9-86.2$ & 67.3 & $52.0-80.5$ & 2.2 \\
\hline & & AHI> 30/h & 81.8 & $59.7-94.8$ & 60.6 & $47.3-72.9$ & 2.0 & 0.4 \\
\hline
\end{tabular}

Legend: Clas. OSA - Classification of Obstructive Sleep Apnea, E - specificity, 95\% Cl - confidence interval, LR - likelihood ratio (positive and negative), S - sensitivity, DV - cut off value.

had duplicate exams, and seven for lack of data in the medical records. We were left with a sample of 83 individuals, with full clinical data relating to the $\mathrm{SB}$, in addition to polysomnographic records of good technical standards.

In Table 1, we find the characteristics of the sample in relation to the quantitative variables. It is worth noting that none of these showed normal distribution, despite the values not being too diverse for the respective mean and median.

Qualitative variables that are part of the SB are described in Table 2. Our sample is formed by $56.6 \%$ men, all of which reported snoring, and only four women, who denied the symptom. Few patients met the obesity criterion, but the discriminatory value considered was $35.0 \mathrm{~kg} / \mathrm{m}^{2}$. However, $65.1 \%$ had a BMI in the overweight or pre-obesity range. Fatigue was reported by $69.9 \%$ of individuals. We also found that $37.3 \%$ had neck circumference (NC) greater than 40 $\mathrm{cm}$. Apnea witnessed by a third party was reported by $63.9 \%$ of the individuals investigated. Regarding the presence of Hypertension, 39.8\% had a positive record. The presence frequencies of the SB variables and their comparisons by gender are described in Table 2, in which we see that only BMI and Observed Apnea behaved similarly between men and women.

We found $89.0 \%$ of the patients had $\geq 3$ positive answers to the $\mathrm{SB}$, and $50.5 \%$ had $\geq 5$ positive answers.

In Table 3, we can see the relative frequencies and averages of the SB items for each of the ranges of positive responses. As expected, in most cases, there is an elevation of the values with the increase of positive answers, although, in some items, we did not observe this behavior.

Only $16.9 \%$ of the cases had a negative diagnosis for OSA (AHI $>5 / h$ ) based on the PSG; 32 patients (39\%) had an AHI between 5 and 15/h, 16 (19\%) were between 16 and 30/h, and 21 (25\%) had an AHI greater than 30/h. If we analyze the DV of $\mathrm{AHI}>15 / \mathrm{h}$, we find a total of $44.5 \%$ of the exams that fall into this category.

The SB performance in our sample, using $\mathrm{AHI}>15 / \mathrm{h}$ as reference, is described in Table 4 , with the respective sensitivity, specificity, and likelihood ratios for each DV.

An SB value greater than or equal to four positive answers showed satisfatory accuracy, considering an AHI greater than $5 / \mathrm{h}, 15 / \mathrm{h}$, or $30 / \mathrm{h}$ (Table 5). The best balance between $\mathrm{S}$ and $\mathrm{E}$, with an AUC of 0.73 with 95\% CI from 0.619 to 0.835 , was obtained with four positive answers to the SB in all three AHI cutoff values.

\section{DISCUSSION}

The characteristics of our sample regarding the predominance of men, overweight, median age and AHI $>15 / h$ were similar to those found in a similar study conducted in a population from a Sleep Disorder Clinic in Latin America ${ }^{16}$. Other studies found in our literature review also used samples with similar characteristics to ours ${ }^{2,17-19}$.

All patients in the sample had some complaint, sign, or symptom related to OSA. Knowing that an $\mathrm{AHI}>5 / \mathrm{h}$ in the presence of symptoms is already a diagnostic criterion for the syndrome, our sample showed a high probability for the disease. One of the possible biases in this study was the fact that most of our patients were diagnosed with moderate and severe OSA. We attribute this predominance to the clinical selection for the PSG by our professionals in the Sleep Clinic, who prioritize more severe patients, due to the great difficulty to perform the examination, a problem that is present in the entire Brazilian public health system. Another possible problem is the low number of individuals with PSG that excluded an OSA diagnosis. Thus, we chose to evaluate the criteria in relation to an AHI $>15 / \mathrm{h}$, so that the sample is more equally distributed regarding the number of cases in each group and given the ability of the PSG alone to identify the disease with a value of $\mathrm{AHI}>15 / \mathrm{h}$.

In our study, we found $89.1 \%$ of patients had three or more positive answers to the questionnaire, thus considered in the OSA high-risk range. A possible explanation is the fact that this study was carried out in a care center specialized in Sleep Medicine. 
For the SB, the DV of $\geq 4$ positive answers was found to have the highest accuracy for all values of AHI. We believe, however, that the $\geq 3$ value is likely to be adequate to maintain a greater sensitivity for a screening test. For a discriminatory value $\geq 4$, we found sensitivities of $60.8 \%, 72.9 \%$, and $81.8 \%$, and specificities of $100 \%, 67.3 \%$, and $60.6 \%$ for $\mathrm{AHI}>5 / \mathrm{h},>15 / \mathrm{h}$, and $>30 / \mathrm{h}$, respectively. Our findings differ from those of the original study, which presented, for a DV of three or more positive SB answers, greater sensitivity of $83.6 \%$, $92.9 \%$, and $100 \%$, and a lower specificity: $56.4 \%, 43.0 \%$, and $37.0 \%$ for the same values of $\mathrm{AHI}^{8}$. However, there was an overlap in the confidence intervals, which shows that the difference may not exist. In addition, the sample of the other study comprised a pre-operative population, not from a sleep clinic. Although we found a different DV, if we look at the sensitivity and specificity in our sample at $\geq 3$ positive SB answers, we would have $\mathrm{S}=84.5 \%, 86.4 \%$, and $91.3 \%$; $\mathrm{E}=57.1 \%$, $30.4 \%$, and $28.3 \%$ for the same AHIs, which are more similar to the sample of said study. In a review article of the SB criteria, the accuracy of a DV $\geq 4$ positive answers is described with a sensitivity of $60.1 \%, 68.0 \%$, and $79.1 \%$, and specificity of $58.8 \%, 55.2 \%$, and $51.4 \%{ }^{11}$, thus a sensitivity very similar to ours, but some differences in the specificities, although there was some overlapping in the confidence interval.

A very recent study from Minneapolis, Minnesota, with 234 patients, identified in its sample a mean age of 55.9 years, the prevalence of males $(67.1 \%$ of the sample), excessive daytime sleepiness in $86.8 \%$ of the patients, Hypertension in $50.9 \%$, and $64.9 \%$ of patients tested with a type III apparatus presented respiratory disorders (AHI)>15/h. All these parameters are higher than those found by us, with the exception of the presence of snoring and Observed Apnea, which in our sample were more prevalent. The study concluded that the Stop-Bang is a poor instrument to discriminate patients with RDI $>15 / \mathrm{h}$ because its AUC ROC was 0.62 with $95 \% \mathrm{CI}$ of 0.55 to $0.68^{20}$. We found a higher AUC of 0.73 with $95 \%$ CI from 0.619 to 0.835 , unlike the study described.

Our results make us continue to understand that the SB screening to identify OSA patients has a predictive value, even though we know that data provided by sleep monitoring equipment have better performance in the diagnosis. However, the SB is easier, more convenient, and quicker to obtain. So, if it can be used to at least rule out patients, we can spare the need for more exams in a given group of individuals ${ }^{20}$.

\section{CONCLUSION}

We conclude that the number of positive answers to the SB provides us safe parameters that can be used as screening instruments for Sleep Apnea Syndrome and guide the initial conduct of cases. In our sample, the value of four or more positive answers had the best performance in identifying patients with an $\mathrm{AHI}>15 / \mathrm{h}$.

\section{RESUMO}

OBJETIVO: Avaliar o desempenho no Questionário Stop-Bang (QSB) em pacientes brasileiros para rastrear a Apneia Obstrutiva do Sono.

MÉTODO: Estudo transversal, com análise histórica e consecutiva de todos os pacientes que realizaram exames de polissonografia pelo Setor de Sono da Otorrinolaringologia e da Cardiopulmonar (LabSono) do Hospital Universitário Gaffrée e Guinle (HUGG), no período de 17/10/2011 a 16/04/2015. As variáveis referentes ao QSB foram colhidas por pesquisa direta nos prontuários dos pacientes.

RESULTADOS: Numa casuística de 83 pacientes, encontramos amostras semelhantes a outros estudos realizados em Centros Especializados em Medicina do Sono, com características da população semelhantes aos estudos feitos na América Latina. Homens e mulheres só se comportaram de forma semelhante em relação à presença de apneias presenciadas e o índice de massa corporal, com um predomínio de mulheres com hipertensão arterial sistêmica sobre os homens. Em nosso estudo, o valor discriminatório de quatro ou mais respostas positivas ao questionário mostrou o melhor desempenho em identificar pacientes com um índice de apneia/hipopneia por hora maior do que 15/h, obtendo sensibilidade de 72,97\% (55,9\% - 86,2\%) e especificidade de 67,39\% (52,0\% - 80,5\%).

CONCLUSÕES: O QSB mostrou-se, em nossa amostra, um bom instrumento de rastreio da Síndrome da Apneia Obstrutiva do Sono. PALAVRAS-CHAVE: Apneia obstrutiva do sono. Síndromes da apneia do sono. Inquéritos e questionários. Polissonografia. Diagnóstico.

\section{REFERENCES}

1. Franklin KA, Lindberg E. Obstructive sleep apnea is a common disorder in the population: a review on the epidemiology of sleep apnea. J Thorac Dis. 2015;7(8):1311-22.
2. Young T, Evans L, Finn L, Palta M. Estimation of the clinically diagnosed proportion of sleep apnea syndrome in middle-aged men and women. Sleep. 1997;20(9):705-6. 
3. Kushida CA, Efron B, Guilleminault C. A predictive morphometric model for the obstructive sleep apnea syndrome. Ann Intern Med. 1997;127(8 Pt 1):581-7.

4. Kushida CA, Littner MR, Morgenthaler T, Alessi CA, Bailey D, Coleman I, $\mathrm{J}$, et al. Practice parameters for the indications for polysomnography and related procedures: an update for 2005. Sleep. 2005;28(4):499-521.

5. Flemons WW, Douglas NJ, Kuna ST, Rodenstein DO, Wheatley J. Access to diagnosis and treatment of patients with suspected sleep apnea. Am Respir Crit Care Med. 2004;169(6):668-72.

6. Netzer NC, Stoohs RA, Netzer CM, Clark K, Strohl KP. Using the Berlin Questionnaire to identify patients at risk for the sleep apnea syndrome. Ann Intern Med. 1999;131(7):485-91.

7. Chung $F$, Elsaid $H$. Screening for obstructive sleep apnea before surgery: why is it important? Curr Opin Anaesthesiol. 2009;22(3):405-11.

8. Chung F, Yegneswaran B, Liao P, Chung SA, Vairavanathan S, Islam S, et al. STOP questionnaire: a tool to screen patients for obstructive sleep apnea. Anesthesiology. 2008;108(5):812-21.

9. Duarte RLM, Fonseca LBM, Magalhaes-da-Silveira FI, Silveira EAD, Rabahi MF. Validation of the STOP-Bang questionnaire as a means of screening for obstructive sleep apnea in adults in Brazil. ) Bras Pneumol. 2017;43(6):456-63.

10. Berry RB, Brooks R, Gamaldo CE, Harding SM, Marcus C, Vaughn B. The AASM manual for the scoring of sleep and associated events. Rules, terminology and technical specifications. Darien: American Academy of Sleep Medicine; 2012

11. Chung F, Yang Y, Brown R, Liao P. Alternative scoring models of STOP-bang questionnaire improve specificity to detect undiagnosed obstructive sleep apnea. J Clin Sleep Med. 2014;10(9):951-8.

12. Software M. MedCalc statistical software version 16.2.0 [Statistical Software]. Ostend, Belgium; 2016. Available from: https://www.medcalc.org.

13. Bland JM, Altman DG. Correlation, regression, and repeated data. BMJ. 1994;308(6933):896.

14. Fletcher RH, Fletcher SW. Managed care and medical education. Lancet. 1996;348(9033):1003-4.

15. Wagner EH, Austin BT, Von Korff M. Improving outcomes in chronic illness. Manag Care Q. 1996;4(2):12-25.

16. Saldías PF, Jorquera AJ, Diaz PO. Predictive value of clinical features and nocturnal oximetry for the detection of obstructive sleep apnea syndrome. Rev Med Chil. 2010;138(8):941-50.

17. Pereira EJ, Driver HS, Stewart SC, Fitzpatrick MF. Comparing a combination of validated questionnaires and level III portable monitor with polysomnography to diagnose and exclude sleep apnea. | Clin Sleep Med. 2013;9(12):1259-66

18. Caffo B, Diener-West M, Punjabi NM, Samet |. A novel approach to prediction of mild obstructive sleep disordered breathing in a population-based sample: the Sleep Heart Health Study. Sleep. 2010;33(12):1641-8.

19. Chai-Coetzer CL, Antic NA, Rowland LS, Catcheside PG, Esterman $A$, Reed RL, et al. A simplified model of screening questionnaire and home monitoring for obstructive sleep apnoea in primary care. Thorax. 2011;66(3):213-9

20. Kunisaki KM, Bohn OA, Wetherbee EE, Rector TS. High-resolution wrist-worn overnight oximetry has high positive predictive value for obstructive sleep apnea in a sleep study referral population. Sleep Breath. 2016;20(2):583-7. 